\title{
Removal of uracil by uracil DNA glycosylase limits pemetrexed cytotoxicity: overriding the limit with methoxyamine to inhibit base excision repair
}

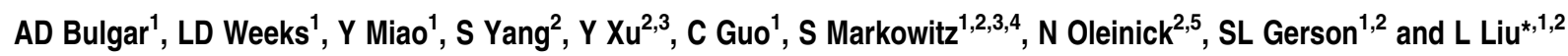

Uracil DNA glycosylase (UDG) specifically removes uracil bases from DNA, and its repair activity determines the sensitivity of the cell to anticancer agents that are capable of introducing uracil into DNA. In the present study, the participation of UDG in the response to pemetrexed-induced incorporation of uracil into DNA was studied using isogenic human tumor cell lines with or without UDG (UDG ${ }^{+I+} / \mathrm{UDG}^{-l-}$ ). $\mathrm{UDG}^{-l-}$ cells were very sensitive to pemetrexed. Cell killing by pemetrexed was associated with genomic uracil accumulation, stalled DNA replication, and catastrophic DNA strand breaks. By contrast, UDG ${ }^{+l+}$ cells were $>10$ times more resistant to pemetrexed due to the rapid removal of uracil from DNA by UDG and subsequent repair of the resultant AP sites (abasic sites) via the base excision repair (BER). The resistance to pemetrexed in $\mathrm{UDG}^{+l+}$ cells could be reversed by the addition of methoxyamine (MX), which binds to AP sites and interrupts BER pathway. Furthermore, MX-bound AP sites induced cell death was related to their cytotoxic effect of dual inactivation of UDG and topoisomerase Ila, two genes that are highly expressed in lung cancer cells in comparison with normal cells. Thus, targeting BER-based therapy exhibits more selective cytotoxicity on cancer cells through a synthetic lethal mechanism.

Cell Death and Disease (2012) 3, e252; doi:10.1038/cddis.2011.135; published online 12 January 2012

Subject Category: Cancer

Pemetrexed, an antifolate, inhibits several key folate-dependent enzymes in the thymidine and purine biosynthetic pathways, leading to the accumulation of dUMP and the misincorporation of uracil into DNA. ${ }^{1-3}$ Incorporated uracil bases are recognized and excised by uracil DNA glycosylase (UDG). ${ }^{4-6}$

UDG is a conserved DNA repair protein expressed in all types of human cells. ${ }^{7}$ It specifically removes uracil from DNA and protect cells from cytotoxicity and mutagenicity. Human UDG is encoded by the UNG gene. Alternative promoter usage and splicing of this gene produces two different isoforms: the mitochondrial UNG1 and the nuclear UNG2. ${ }^{8}$ Nuclear UDG (UNG2) is the predominant form in cells and represents $>90 \%$ of the total enzyme activity. Therefore, UDG used in this article refers to UNG2. Nuclear UDG activity is subject to cell cycle-dependent regulation and shows a marked increase during the S-phase. ${ }^{9}$ During the S-phase, UDG is localized in replication foci and interacts with PCNA (proliferating cell nuclear antigen) and RPA (replication protein $A$ ), two proteins that are required to form functional replication forks. ${ }^{9}$ This suggests that the UDG removal of incorporated uracil may directly link to the progression of the replication fork. ${ }^{10,11}$ In addition, UDG has recently been shown to promote the assembly of human centromere protein A (CENP-A). As CENP-A is an essential protein required for chromosome segregation during mitosis, the association between UDG and CENP-A implies that UDG may be involved in cell proliferation. ${ }^{12}$

The base excision repair (BER) pathway is initiated following the removal of a base lesion by a DNA glycosylase. ${ }^{13}$ Glycosylase excision of the damaged base proceeds via hydrolytic cleavage of the $\mathrm{N}$-glycosidic bond, leaving the sugar-phosphate backbone intact and producing an abasic site (AP site). ${ }^{14,15}$ The resultant AP site is processed by AP endonuclease 1 (APE1), which generates a single-strand break containing a $5^{\prime}$-dRP residue and a $3^{\prime}$-hydroxyl group. The completion of BER occurs by short-patch (single nucleotide) or long-patch (2-13 nucleotides) repair pathways involving DNA polymerase gap filling and DNA ligation. BER is the most efficient mechanism for repairing a variety of base lesions, including those induced by chemotherapeutic agents, thereby rendering tumor cells resistant to DNA-damaging chemotherapeutic agents. ${ }^{16-18}$ To overcome BER-conferred drug resistance, methoxyamine $(\mathrm{MX})$ has been developed as an active inhibitor of BER. ${ }^{19} \mathrm{MX}$ reacts specifically with the aldehyde group in the sugar moiety of the AP site, forming an MX-bound AP-site. This structurally modified AP site is refractory to the repair activity of $A P E 1,{ }^{20,21}$ leading to the interruption of the BER pathway. MX has been shown to potentially enhance the therapeutic efficacy of various

\footnotetext{
${ }^{1}$ Department of Medicine, Division of Hematology/Oncology, Case Western Reserve University, Cleveland, OH, USA; ${ }^{2}$ Case Comprehensive Cancer Center, Case Western Reserve University, 2103 Cornell Road, Cleveland, OH 44106, USA; ${ }^{3}$ Department of Chemistry, Cleveland State University, Cleveland, OH, USA; ${ }^{4}$ Department of Genetics, Case Western Reserve University, Cleveland, OH, USA and ${ }^{5}$ Department of Radiation Oncology, Case Western Reserve University, Cleveland, OH, USA ${ }^{*}$ Corresponding author: L Liu, Department of Medicine, Division of Hematology and Oncology, Case Western Reserve University, Cleveland, 10900 Euclid Avenue, OH 44106, USA. Tel: + 1216368 5696; Fax: +1 216368 1166; E-mail: Ixl32 @ case.edu

Keywords: UDG; base excision repair; AP sites; methoxyamine

Abbreviations: UDG, uracil DNA glycosylase; BER, base excision repair; MX, methoxyamine; Topo II $\alpha$, topoisomerase II $\alpha$; PCNA, proliferating cell nuclear antigen; RPA, replication protein A

Received 30.8.11; revised 09.11.11; accepted 09.11.11; Edited by RA Knight
} 
DNA-damaging chemotherapeutic agents. ${ }^{22-25}$ It is currently being evaluated in multiple clinical trials (as TRC102, TRACON Pharmaceuticals, Inc., San Diego, CA, USA) and has completed phase-I testing in combination with pemetrexed.

In the present study, we investigated the impact of UDG and BER on cell sensitivity to pemetrexed using isogenic UDGproficient and -deficient human cancer cells. Although pemetrexed has multiple targets, the different responses to pemetrexedin $\mathrm{UDG}^{+/+}$and $\mathrm{UDG}^{-/-}$cells were investigated only with respect to the levels of uracil-DNA produced by pemetrexed. We also explored the inhibition of BER by MX as a novel strategy to enhance the therapeutic efficacy of pemetrexed, although $\mathrm{MX}$ is expected to potentiate other anticancer agents capable of inducing uracil incorporation into DNA.

\section{Results}

UDG activity determines the level of uracil retained in DNA. To correlate UDG activity with the cytotoxicity of pemetrexed, comparative studies were performed in $\mathrm{UDG}^{+/+}$and $\mathrm{UDG}^{-1-}$ cells. We first confirmed the UDG activity in these cells using an in vitro glycosylase cleavage assay, in which oligonucleotide substrates containing uridine residues were incubated with either purified UDG/APE1 enzymes or cell extracts. As shown in Figure 1a, after the reaction with fluorescent probe-labelled oligonucleotide substrates (40-mer) containing U:G mispairs, both purified UDG/APE1 enzymes and cell extracts from $\mathrm{UDG}^{+/+}$cells produced cleaved DNA fragments as an 18-mer band, which resulted from the removal of uracil bases by UDG and subsequent incision of the resultant AP sites by APE1. By contrast, no cleaved fragments were observed in $\mathrm{UDG}^{-/-}$ cell extracts after incubation with an even higher concentration of cell extracts. $D^{\text {flag }}$ cells were capable of removing uracil bases, which were derived from $\mathrm{UDG}^{-/-}$ cells by restoring UDG activity.

We next determined the levels of uracil in the DNA of $\mathrm{UDG}^{+1+}$ and $\mathrm{UDG}^{-1-}$ cells following pemetrexed exposure using HPLC/MS/MS. There was an inverse relationship between UDG activity and the level of uracil bases in the DNA (Figure 1b). A significant amount of uracil was detected in $\mathrm{UDG}^{-1-}$ cells, which correlated with the duration of
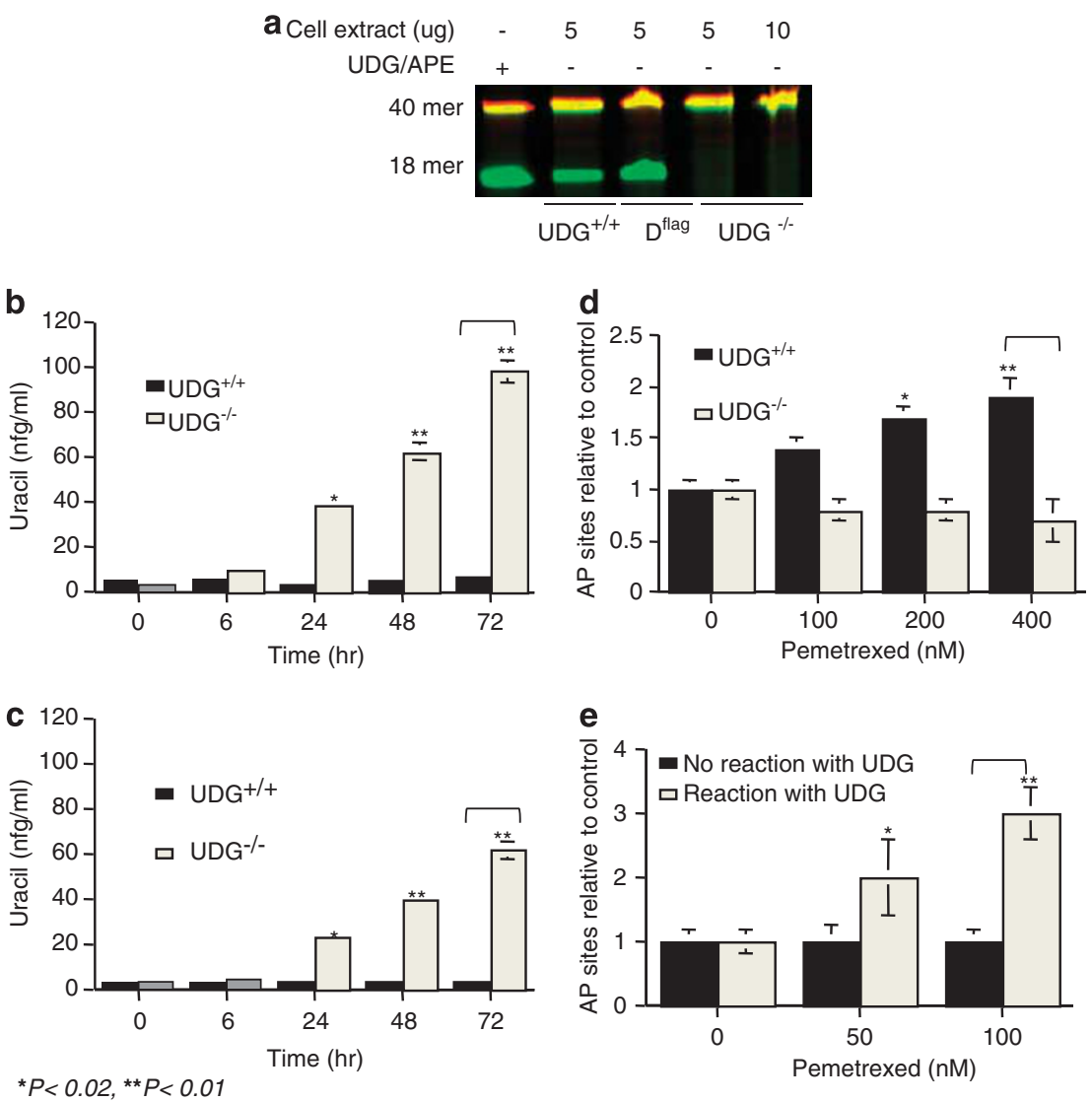

Figure 1 UDG activity determines the levels of uracil and AP sites in DNA. (a) UDG activity assay in vitro. Oligonucleotide duplexes containing U:G were incubated with cell extracts $(5-10 \mu \mathrm{g})$ from UDG ${ }^{+1+}, \mathrm{DLD} 1^{\text {flag }}$, and UDG ${ }^{-1-}$ cells at $37^{\circ} \mathrm{C}$ for $1 \mathrm{~h}$. Reaction products were resolved by electrophoresis through denaturing $20 \%$ polyacrylamide gels. (b) Incorporated uracil detected in $\mathrm{UDG}^{+/+}$and $\mathrm{UDG}^{-1-}$ cells by HPLC/MS/MS analysis. Cells were treated with pemetrexed (10 $\left.\mu \mathrm{M}\right)$ for $6,24,48$, and $72 \mathrm{~h}$. Cells were harvested and $40 \mu \mathrm{g}$ of extracted DNA were in vitro reacted with purified UDG (10 U) for $2 \mathrm{~h}$. (c) Cells were treated with 5 -FU $(10 \mu \mathrm{M})$ for $6,24,48$, and $72 \mathrm{~h}$. Uracil was quantified in the reaction product by LC-MS analysis. (d) AP site formed by pemetrexed in UDG ${ }^{+1+}$ and UDG ${ }^{-1-}$ cells. Cells were treated with pemetrexed $(0-400 \mathrm{nM})$ for $24 \mathrm{~h}$. DNA was extracted and AP sites measured by ARP reagent. (e) AP site detected in DNA of UDG ${ }^{-1-}$ cells after reacted with purified UDG in vitro. Cells were treated with pemetrexed $(0-100 \mathrm{nM})$ for $24 \mathrm{~h}$ and $40 \mu \mathrm{g}$ DNA extracted from cells was in vitro reacted with purified UDG (10 U) for $2 \mathrm{~h}$ and AP sites were measured using ARP. Results are representative of three independent experiments 
pemetrexed exposure. By contrast, the detectable uracil in the DNA was very low in $\mathrm{UDG}^{+/+}$cells, suggesting rapid and efficient removal of the incorporated uracil. Similarly, a greater retention of uracil in $\mathrm{UDG}^{-/-}$cells than in $\mathrm{UDG}^{+/+}$cells (Figure 1c) was detected following exposure to 5-fluorouracil (5-FU), a well-known thymidylate synthase inhibitor capable of introducing uracil into DNA through imbalanced nucleotide pools.

The AP sites formed by pemetrexed were measured in cells, which are a surrogate marker for UDG activity in the cells. As shown in Figure 1d, a dose-dependent formation of AP sites in DNA was detected in $\mathrm{UDG}^{+/+}$but not in $\mathrm{UDG}^{-/-}$ cells. The lack of detectable AP sites in $\mathrm{UDG}^{-1-}$ cells is presumably due to the absence of UDG activity to remove uracil, resulting in the accumulation of uracil bases in the DNA. To confirm this, pemetrexed-induced AP sites in $\mathrm{UDG}^{-1-}$ DNA were analyzed after incubation with purified UDG enzymes in vitro. As shown in Figure 1e, increased AP sites were detected as a function of pemetrexed doses.

UDG activity determines cell sensitivity to pemetrexed. To determine the correlation between the expression of UDG and the sensitivity to pemetrexed, the cytotoxic effect of pemetrexed was examined in $\mathrm{UDG}^{+/+}$and $\mathrm{UDG}^{-1-}$ cells with a clonogenic assay. $\mathrm{UDG}^{-1-}$ cells were 10 times more sensitive to pemetrexed than $\mathrm{UDG}^{+/+}$cells (Figure 2a). The $\mathrm{IC}_{50}$ value for pemetrexed was $20 \mathrm{nM}$ in $\mathrm{UDG}^{-1-}$ cells, compared with $210 \mathrm{nM}^{\text {in }} \mathrm{UDG}^{+/+}$cells. The killing effect of pemetrexed in $\mathrm{UDG}^{-1-}$ cells was reversed when UDG activity was restored in $D^{\text {flag }}$ cells. Similarly,
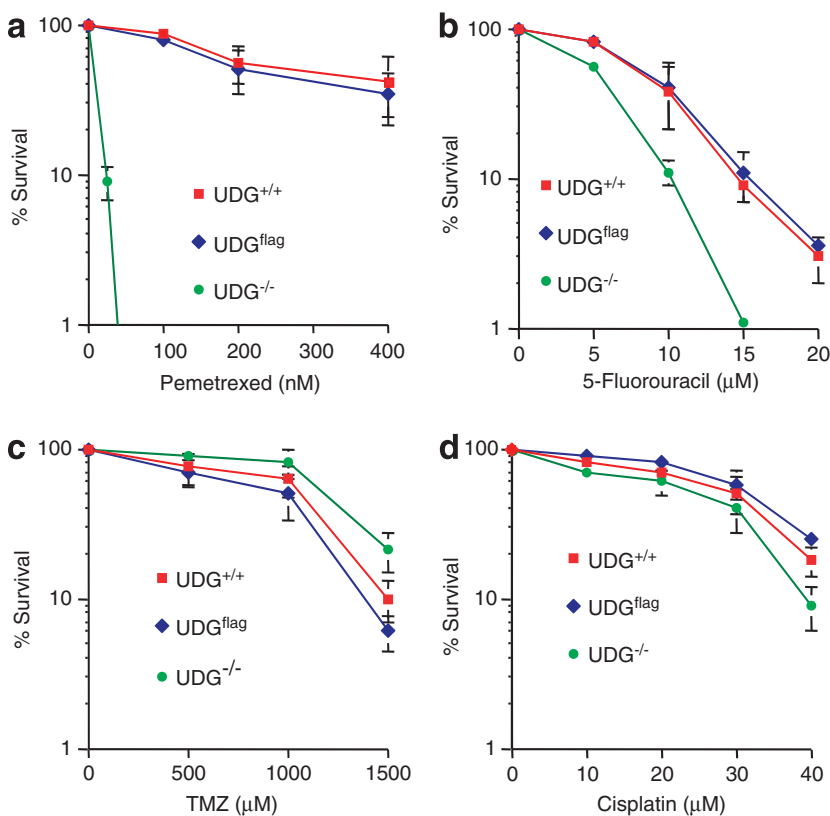

Figure 2 Comparison of cell sensitivity with chemotherapeutic agents between $\mathrm{UDG}^{+1+}$ and $\mathrm{UDG}^{-1-}$ cells. The cytotoxicity induced by different chemotherapeutic agents was analyzed by clonogenic formation assay in UDG-proficient or -deficient cells (a) pemetrexed treatment $(0-400 \mathrm{nM})$; (b) 5 -FU treatment $(0-20 \mu \mathrm{M})$; (c) temozolomide treatment $(0-1500 \mu \mathrm{M} ; \quad P$-value $=0.687)$; and (d) cisplatin treatment $(0-40 \mu \mathrm{M}, P$-value $=0.753)$. Results are representative of three independent experiments
$\mathrm{UDG}^{-1-}$ cells were more sensitive to 5-FU than either $\mathrm{UDG}^{+1+}$ or $\mathrm{D}^{\text {flag }}$ cells (Figure $2 \mathrm{~b}$ ). By contrast, there was no significant difference in sensitivity to temozolomide, an alkylating agent, or cisplatin, a crosslinking agent (Figures 2c and $\mathrm{d}$ ), between $\mathrm{UDG}^{+/+}$and $\mathrm{UDG}^{-/-}$cells. Thus, results suggest that UDG activity specifically impacts the cytotoxicity of anticancer agents that are capable of inducing the incorporation of uracil bases in DNA.

The accumulation of incorporated uracil in DNA stalls DNA replication. To elucidate the underlying mechanisms responsible for pemetrexed's cytotoxicity, we first examined cell cycle progression in response to pemetrexed. As shown in Figure 3a, pemetrexed ( $25 \mathrm{nM})$ caused the arrest of $\sim 25 \%$ and $36 \%$ of $\mathrm{UDG}^{-1-}$ cells in the S-phase at 6 and $24 \mathrm{~h}$, respectively (Figure 3a). The S-phase arrest lasted more than $72 \mathrm{~h}$. At this time point, $35 \%$ of the cells were still in the S-phase and $\sim 22 \%$ of the cells had undergone apoptosis (subG1). By contrast, progression of the cell cycle in $\mathrm{UDG}^{+/+}$cells was only slightly affected by this dose of pemetrexed (Figure $3 b$ ). The effect of pemetrexed on cell killing was further analyzed by annexin V staining at $24 \mathrm{~h}$ after cells were treated with $50 \mathrm{nM}$ of pemetrexed. Results revealed that pemetrexed at the same concentration induced $30 \%$ of cell death in $\mathrm{UDG}^{-1-}$ cells compared with $5 \%$ in $\mathrm{UDG}^{+/+}$cells (Figures $4 \mathrm{a}$ and $\mathrm{b}$ ).

We next examined a network of proteins responsible for DNA damage checkpoints following exposure to pemetrexed. We found that phospho-Chk1 (Ser345) was significantly increased in $\mathrm{UDG}^{-1-}$ cells (Figure $3 \mathrm{c}$ ) but not in $\mathrm{UDG}^{+/+}$ cells (Figure $3 d$ ). As a DNA damage checkpoint kinase, the induction of phosphor-Chk1 suggests that pemetrexed stalls replication forks in UDG ${ }^{-1-}$ cells. We also noted that in both cell lines, phospho-histone H3 (Ser 10), a mitotic marker, increased at $6 \mathrm{~h}$ and decreased at $24 \mathrm{~h}$ following exposure to pemetrexed. Interestingly, the periodic fluctuation of phosphorylation of histone $\mathrm{H} 3$ was not directly associated with mitotic cell cycle progression. In addition, the induction of phospho-histone $\mathrm{H} 3$ was concomitant with the increase in G1-S-phase-specific cyclin D1. Subsequently, the S-phasespecific cyclin $\mathrm{E}$ was upregulated following the exposure to pemetrexed (Figures $3 \mathrm{c}$ and $\mathrm{d}$ ). It has been reported that inhibition of cell proliferation can regulate histone $\mathrm{H} 3$ phosphorylation and that this modification enables the transcription of genes that are activated as a consequence of a variety of cell-signaling events. ${ }^{26}$ Therefore, our data may suggest that phosphorylation of histone $\mathrm{H} 3$ is an important regulatory mechanism of gene transcription. However, whether the phosphorylation of histone $\mathrm{H} 3$ is linked to transcriptional activation of cyclin proteins in response to DNA damage induced by pemetrexed needs to be further investigated. Although the role of cyclin D1 and E remains to be fully elucidated, they function as the regulators of the G1-S phase entry in response to inhibition of replication-stalled $\mathrm{S}$-phase. Furthermore, the upregulation of phosphor-cdc2 and cyclin B1 also indicates that pemetrexed-induced DNA damage activates the S- and M-phase checkpoints.

In addition, pemetrexed induced an increase in the expression of topoisomerase $\| \alpha$ (topo $\| \alpha$ ) that was much greater in $\mathrm{UDG}^{-/-}$cells than in $\mathrm{UDG}^{+/+}$cells 
a

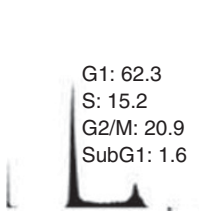

Untreated
UDG $^{-1-}$ cells

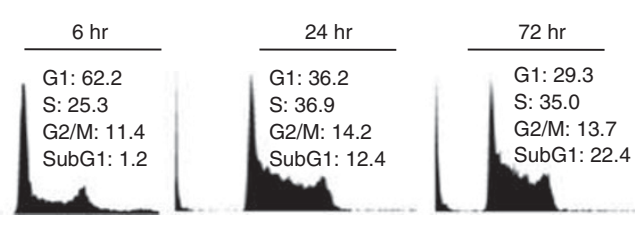

Pemetrexed (25 nM) b

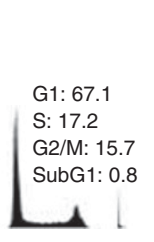

Untreated

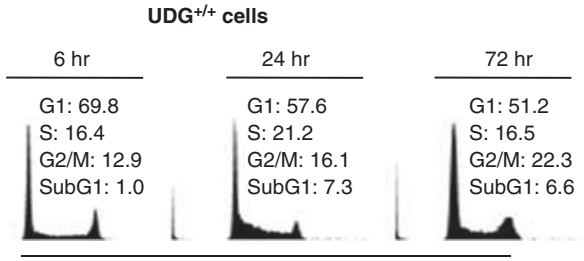

Pemetrexed (25 nM) c

UDG ${ }^{-1-}$ cells

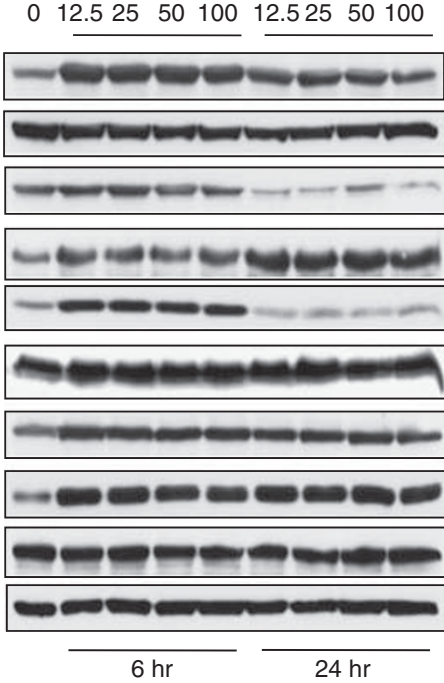

d $\mathrm{UDG}^{+/+}$cells

Pemetrexed (nM) $0 \quad 12.525 \quad 5010012.525 \quad 50100$

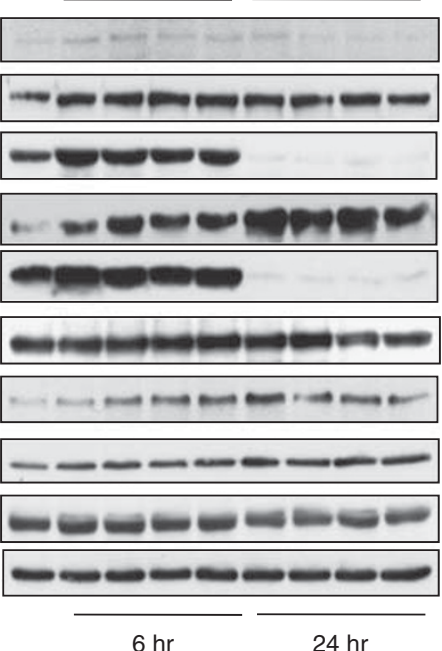

Figure 3 Cellular response to uracil-DNA induced by pemetrexed. Comparison of cell cycle progression before and after treatment with pemetrexed between (a) UDG ${ }^{-1-}$ and (b) UDG ${ }^{+l+}$ cells. Protein alterations in the response to DNA damage, cell cycle progression, and cell death were detected in (c) UDG ${ }^{-1-}$ cells and (d) UDG $^{+1+}$ cells treated with pemetrexed. Cells were collected at 6 and $24 \mathrm{~h}$ after pemetrexed treatment. Results are representative of two independent experiments

(Figures $4 \mathrm{c}$ and $\mathrm{d}$ ). The induction of topo $\mathrm{Il} \alpha$ may be associated with either a global signal of DNA damage or a more specific response to the S-phase arrest. As expected, $\gamma \mathrm{H} 2 \mathrm{AX}$ was markedly increased in $\mathrm{UDG}^{-1-}$ cells, which is a well-known marker of DNA double-strand breaks (DSBs) and an indicator of stalled replication forks and replication fork collapse. $^{27}$ In company with the induction of $\gamma \mathrm{H} 2 \mathrm{AX}$, a significant cleaved PARP (a hallmark of apoptotic cell death) was detected in $\mathrm{UDG}^{-1-}$ cells. The activation of caspase 3,8 and 9 (Figures $4 \mathrm{c}$ and $\mathrm{d}$ ) was then measured. Those are considered to be the key effect of proteases on apoptosis through the degradation of numerous cellular substrates including the cleavage of PARP. Surprisingly, the pemetrexed-induced PARP cleavage appeared to be independent of the caspase pathway. Moreover, survivin was noted to be upregulated in response to pemetrexed. As a member of the inhibitor of apoptosis protein family, survivin has been reported to bind to and inhibit effector caspase-3 and -7 . $^{28}$ Although the direct effect on caspases still remain to be further determined, the induction of survivin may link to the inhibition of caspase 3. Taken together, our results suggest that pemetrexed-induced apoptotic cell death may not be mediated through the caspase pathway or that other cell death regulators are more important in pemetrexed-treated cells. $^{29}$
We further investigated whether uracil-DNA lesions could inhibit DNA replication. Cells were sequentially labeled with the halogenated nucleotides chlorodeoxyuridine (CldU) and iododeoxyuridine (IdU) to stain replication foci. Representative cells are depicted in Figures $5 b$ and c. Compared with replication foci stained with CldU and IdU in untreated cells, a significant reduction in IdU incorporation was observed in $\mathrm{UDG}^{-1-}$ cells following a $6-\mathrm{h}$ exposure to pemetrexed and a further 18-h after incubation, suggesting that pemetrexedinduced accumulation of uracil has the potential to inhibit DNA replication. By contrast, there was no significant change in CldU and IdU incorporation in the replication foci of UDG ${ }^{+1+}$ cells before and after pemetrexed treatment $(25 \mathrm{nM})$. The fluorescence density of IdU or CldU was quantified in UDG ${ }^{-/-}$ and $\mathrm{UDG}^{+/+}$cells by using the $\mathrm{NIH}$ Image $\mathrm{J}$ software $(\mathrm{NIH}$, Bethesda, MD, USA; Figure $5 \mathrm{~d}$ ). The values of the ratio of IdU to CldU indicate that accumulated uracil bases in DNA block DNA replication in $\mathrm{UDG}^{-1-}$ cells.

Blocking BER enhances pemetrexed cytotoxicity. We have shown above that the lack of UDG activity sensitizes tumor cells to antimetabolites. However, UDG deficiency appears to be surprisingly rare in human tumors. In fact, human lung cancer express higher UDG than its corresponding normal tissues. ${ }^{30-32}$ Thus, the removal of 


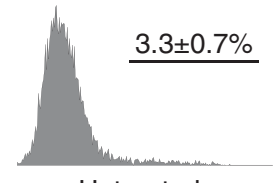

Untreated
UDG $^{-1-}$

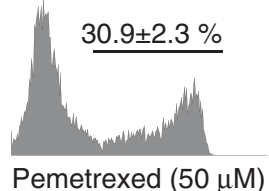

b

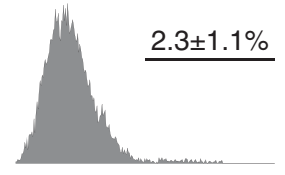

Untreated
$\mathrm{UDG}^{+/+}$

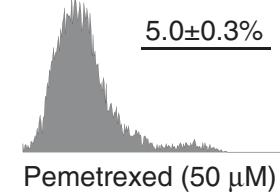

C

012.5255010012 .52550100

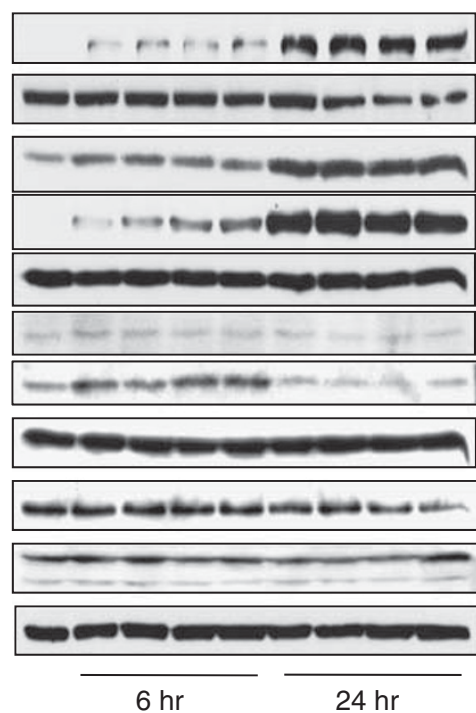

c

UDG $+/$

Pemetrexed (nM) 012.5255010012 .52550100

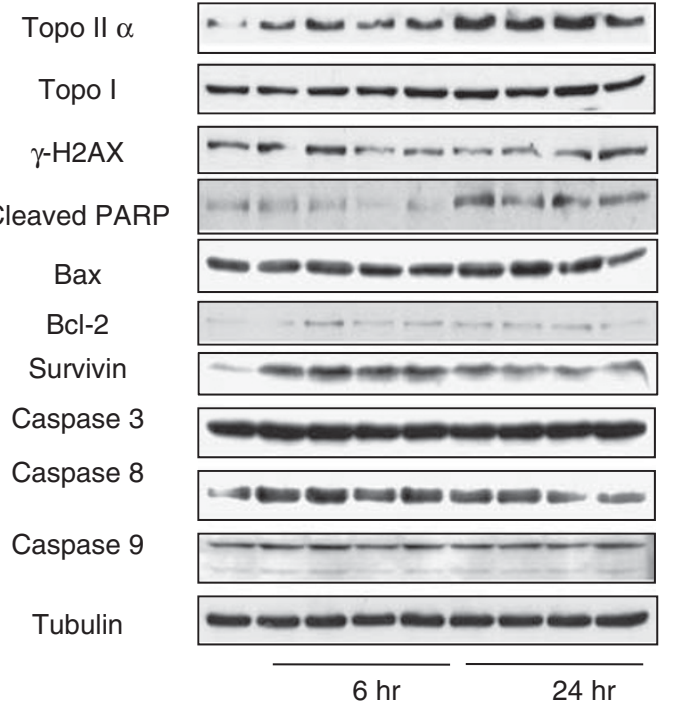

Figure 4 Pemetrexed-induced apoptotic death is independent of caspase pathway. The percentage of cell death induced by pemetrexed using Annexin $\mathrm{V}$ staining in $\mathrm{UDG}^{-1-}$ (a) and $\mathrm{UDG}^{+/+}$cells (b). Protein alterations involved in regulation of apoptotic cell death were detected in (c) $\mathrm{UDG}^{-/-}$cells and (d) $\mathrm{UDG}^{+/+}$cells treated with pemetrexed. Cells were collected at 6 and $24 \mathrm{~h}$ after pemetrexed treatment. Results are representative of two independent experiments

uracil by UDG and subsequent BER activity limits the efficacy of pemetrexedin lung cancer treatment. We next studied a therapeutic strategy to override the UDG-conferred resistance to pemetrexed by interrupting the BER pathway using MX. Cytotoxicity was measured in $\mathrm{UDG}^{+/+}$and $\mathrm{UDG}^{-l-}$ cells after treatment with pemetrexed alone or in combination with $\mathrm{MX}$. MX greatly sensitized $\mathrm{UDG}^{+/+}$cells to pemetrexed and reduced the pemetrexed $\mathrm{IC}_{50}$ value from 220 to $80 \mathrm{nM}$ (Figure 6a). By contrast, no differential sensitivity between pemetrexed alone and in combination with $\mathrm{MX}$ was observed in $\mathrm{UDG}^{-1-}$ cells (Figure $6 \mathrm{~b}$ ). The failure of $\mathrm{MX}$ to potentiate pemetrexed toxicity in $\mathrm{UDG}^{-1-}$ cells can be explained by the fact that, in UDG ${ }^{-l-}$ cells, there are no DNA-binding sites available for $M X$ due to the absence of AP sites in the DNA (Figure 1d). Similar experiments were performed in the human nonsmall cell lung cancer cell lines $\mathrm{H} 460$ and A549 (Figures 6c-e). These two cell lines retain wild-type p53 and harbor a mutation in K-ras but express different levels of UDG. Western blotting revealed that UDG protein levels in A549 were approximately 9- and 17-fold higher than in $\mathrm{H} 460$ cells and normal lung epithelial cells, respectively (Figure 6d). A549 cells were obviously more resistant to pemetrexed than $\mathrm{H} 460$ cells. $I \mathrm{C}_{50}$ values for pemetrexed were $1200 \mathrm{nM}$ in A549, compared with
$110 \mathrm{nM}$ in $\mathrm{H} 460$ cells. MX was capable of enhancing pemetrexed cytotoxicity in both cell lines four- to fivefold (Figure 6e). Thus, although multiple mechanisms may confer resistance to pemetrexed, our results indicated that UDG activity in lung cancer cells is an important factor in pemetrexed-resistance. This was further confirmed by the studies, in which UDG, in H460 cells, was knocked down by siRNA, resulting in the increase in cytotoxicity by threefold (data not shown). Importantly, MX reverses this resistance.

AP sites were detected in $\mathrm{H} 460$ cells following treatment with pemetrexed. As shown in Figure 7a, the formation of AP sites increased as the concentration of pemetrexed increased. Co-treatment with MX formed MX-bound AP sites, resulting in the reduction of ARP (aldehyde-reactive probe)detected $A P$ sites. This is because ARP and $M X$ react competitively with the aldehyde group in AP sites and binding of MX to the AP sites makes them unavailable for ARP binding (Figure 7a). Furthermore, the levels of UDG protein were significantly induced in cells treated with the combination of pemetrexed and MX (Figure 7b). Immunofluorescent staining revealed that the UDG protein was increased in both the cytosol and the nucleus but predominantly accumulated in the nucleus at $24 \mathrm{~h}$ after treatment with the combination (Figure 7c), suggesting that MX-bound AP sites were able to 
a

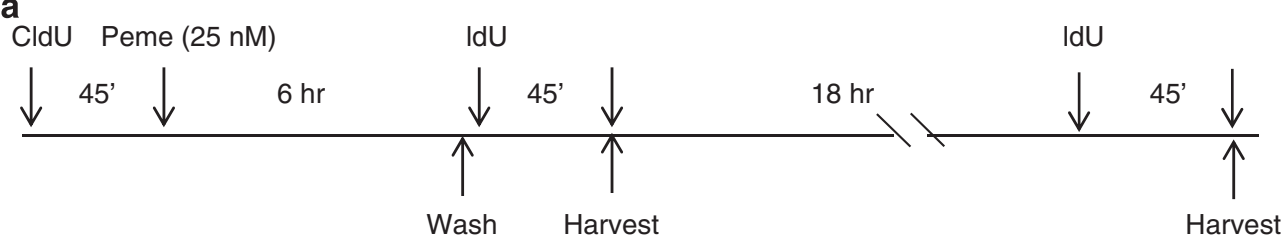

c

b $\mathrm{UDG}^{-/}$sllec CldU
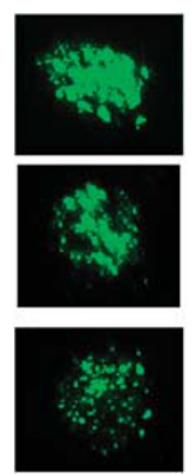

IdU
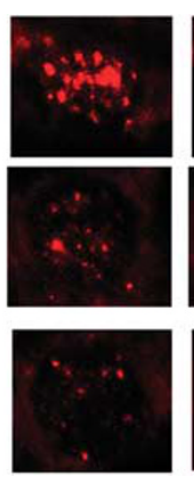

Merge
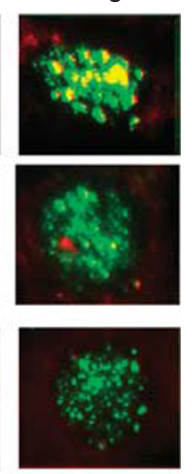

CldU

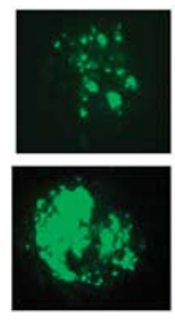

$18 \mathrm{hr}$ post Pemetrexed
C

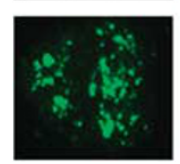

$$
\mathrm{UDG}^{+/+} \text {cells }
$$

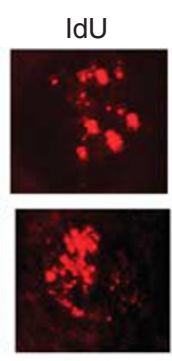

Merge
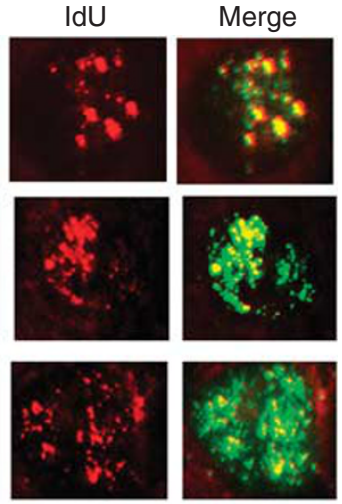

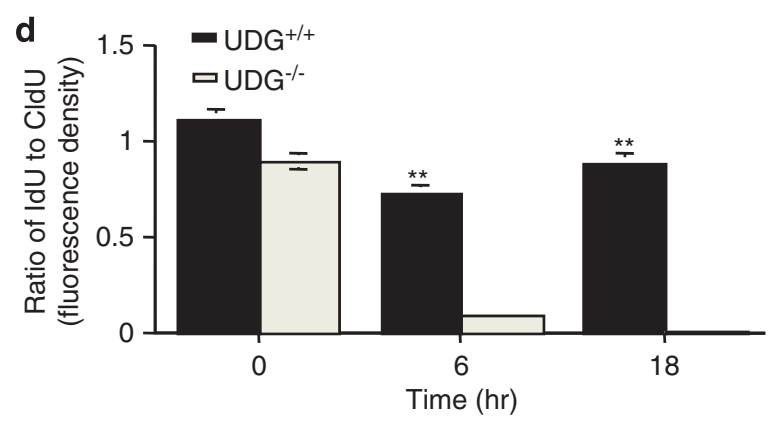

Figure 5 Inhibition of DNA replication induced by pemetrexed. (a) Schematic diagram of the CldU, pemetrexed and IdU pulse treatments. (b) UDG ${ }^{-/-}$and (c) UDG ${ }^{+/+}$ cells were fixed at 6 and $24 \mathrm{~h}$ after treatments and subjected to fluorescent immunostaining. Replication foci were labeled with CldU (green) and IdU (red). Results are representative of two independent experiments. (d) The ratio of IdU to CldU was measured as the ratio of the mean fluorescent density of IdU versus CldU for each cell $(n=40)$

trap or stabilize UDG in DNA. In addition, concomitant inductions of topo $\| \alpha, \gamma \mathrm{H} 2 \mathrm{AX}$, and cleaved PARP were seen in cells treated with the combination of pemetrexed and $M X$ (Figures $7 d$ and e). These results could be explained by our previous findings that MX-bound AP sites were capable of poisoning topo $\| \alpha$ and inducing topo $\| \alpha-$-mediated DNA DSBs, ${ }^{33}$ triggering apoptosis.

\section{MX potentiates the anti-tumour effects of pemetrexed} in vivo. The MX-potentiated antitumour effect of pemetrexed was further tested in vivo using human lung cancer xenografts. As shown in Figure 8, both $\mathrm{H} 460$ and A549 tumors were moderately sensitive to pemetrexed alone. However, the antitumour activity of pemetrexed was significantly enhanced by the combination of pemetrexed $(150 \mathrm{mg} / \mathrm{kg})$ and $M X(4 \mathrm{mg} / \mathrm{kg})$ in these two xenograft tumors. At 15 days, $\mathrm{H} 460$ xenografts treated with PBS (control group) had a mean tumor volume of $2100 \pm 106 \mathrm{~mm}^{3}$, compared with a mean tumor volume of $1726 \pm 176 \mathrm{~mm}^{3}$ or
$543 \pm 82 \mathrm{~mm}^{3}\left({ }^{*} P\right.$-value $\left.<0.02\right)$ in mice treated with either pemetrexed alone or in combination with $\mathrm{MX}$, respectively.

Similarly, MX-potentiated antitumor effect of pemetrexed was observed in A549 xenografts, which was consistent with the in vitro data. In addition, at these doses, mice did not present evidence of systemic toxicity as evaluated by body weight measurements and complete blood count tests (data not shown).

\section{Discussion}

The current study provides evidence that UDG has a profound impact on the cytotoxicity of uracil incorporation into DNA induced by pemetrexed. Because the expression of UDG in lung cancer tissue is high but varies between individuals, UDG activity may be exploitable as a biomarker for predicting susceptibility and response to pemetrexed-related treatment. Moreover, our results demonstrated that the loss of UDG results in the accumulation of uracil in DNA, which stalls replication forks and subsequently induces replication 


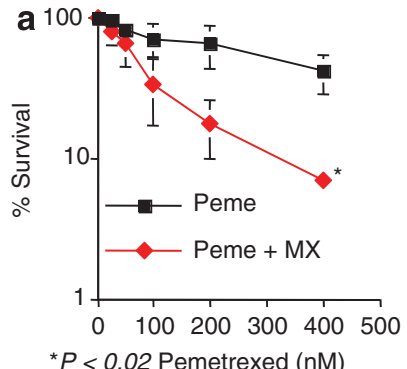

${ }^{*} P<0.02$ Pemetrexed $(\mathrm{nM})$
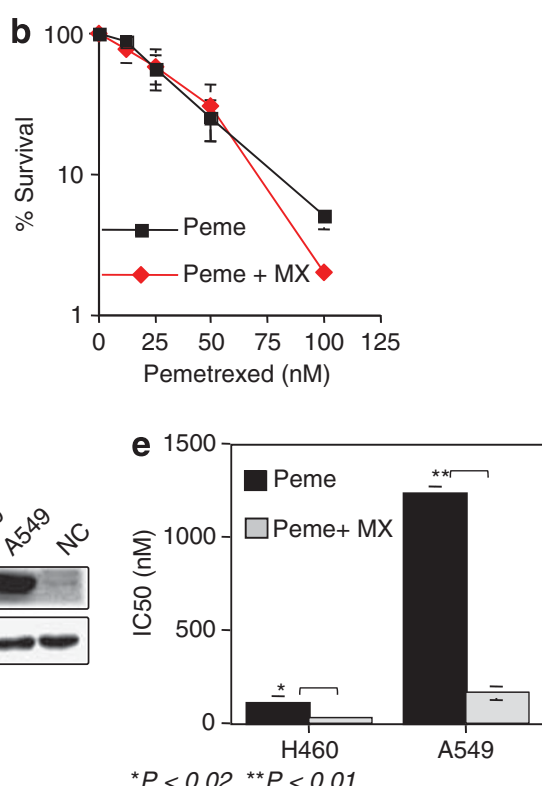

Figure 6 The potentiation of pemetrexed cytotoxicity by MX. (a and $\mathbf{b})$ Cytotoxicity of pemetrexed alone and in combination with MX was examined by a clonogenic survival assay in UDG ${ }^{+/+}$and UDG ${ }^{-/-}$cells. (c) MX potentiated the cytotoxicity of pemetrexed in H460 cells. (d) Comparison of UDG protein levels between H460 and A549 by western blotting assay. (e) Comparison of sensitivity to pemetrexed between $\mathrm{H} 460$ and A549 cells. Results are representative of three independent experiments

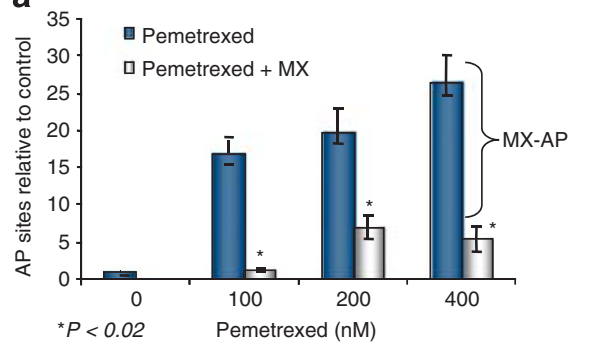

C Untreated

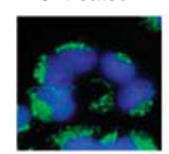

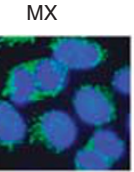

Peme

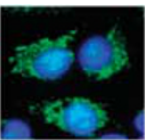

b

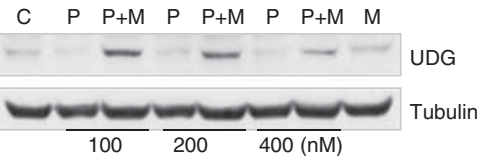

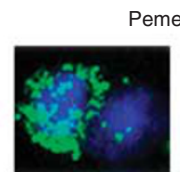

$6 \mathrm{hr}$ d Peme

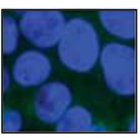

Peme + MX

e

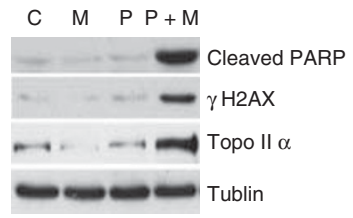

Figure 7 MX-bound AP sites induced by the combination of pemetrexed and MX are lethal DNA lesions. (a) The dose-dependent relationship between the levels of AP sites and the concentrations of pemetrexed. The AP sites in DNA were measured using ARP reagent after $\mathrm{H} 460$ cells were treated with pemetrexed alone (0-400 nM) or in combination with MX $(6 \mathrm{mM})$ for $24 \mathrm{~h}$. MX-bound AP sites were determined by the differences between AP sites induced by pemetrexed alone and the combination of pemetrexed and MX. (b) UDG induction detected in cells treated with the pemetrexed alone and in combination with MX. Cells were collected and UDG protein was measured by western blotting analysis. (c) H460 cells grown on the coverslip were treated with pemetrexed alone (100 nM) and in combination with MX (6 mM) for $24 \mathrm{~h}$ and subjective to the fluorescent immunostaining. The signal of UDG protein (green) was significantly enhanced and localized in nucleus (blue) of cells treated with the combination of pemetrexed and MX. (d) $\gamma \mathrm{H} 2 \mathrm{AX}$ foci formation detected in $\mathrm{H} 460$ cells treated with pemetrexed (100 nM) alone and in combination with MX (6 mM) for $24 \mathrm{~h}$; (e) Induction of the cleaved PARP and $\gamma \mathrm{H} 2 \mathrm{AX}$ proteins was detected by western blotting in cells with the same treatments

collapse, leading to remarkable increases in the killing effect of pemetrexed. These studies lead us to propose that, as a therapeutic target, UDG may offer new avenues for the development of novel anticancer agents.
UDG removal of incorporated uracil links the DNA replication process. The progression of the DNA replication fork can be stopped by various factors, including DNA damage, protein-DNA complexes, and depletion of 

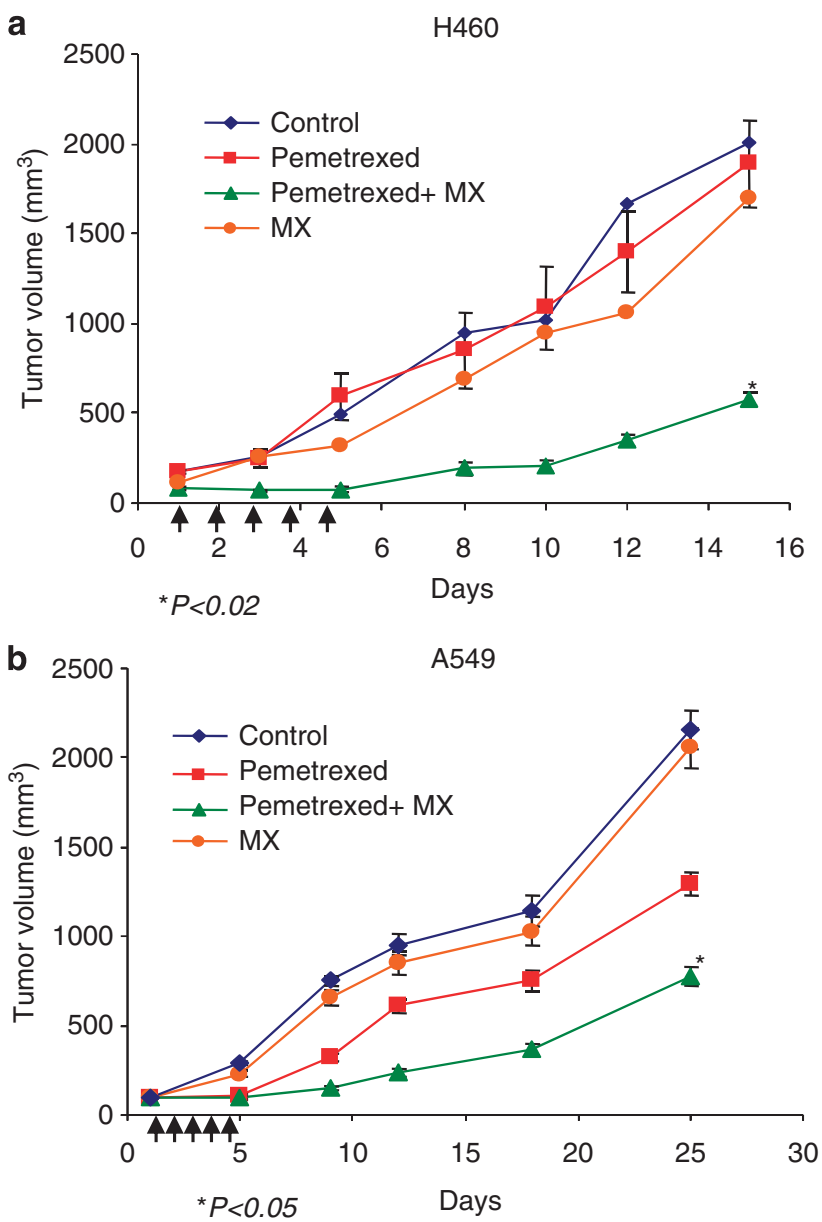

Figure $8 M X$ synergistically enhances antitumor effect of pemetrexed. Human nonsmall cell lung cancer xenografts were grown in athymic nude mice. When tumor volume of $\mathrm{H} 460$ (a) or $\mathrm{A} 549$ (b) reached $100 \mathrm{~mm}^{3}$, mice received the treatment with PBS (control), MX (4 mg/kg), pemetrexed ( $150 \mathrm{mg} / \mathrm{kg}$ ), and pemetrexed plus MX, i.p injection/daily for 5 days. Tumor volume was measured and used to determine the therapeutic effect

nucleotide pools. It has been reported that the role of BER becomes critical when damaged bases are produced or persist at replication forks. ${ }^{34}$ On the basis of our results, we suggest that the accumulation of uracil bases in DNA would stall DNA replication forks, which immediately activates DNA damage checkpoint pathways and robust mechanisms of DNA damage repair. The following lines of evidence support this conclusion. First, using UDG ${ }^{+/+}$and $\mathrm{UDG}^{-1-}$ cells, we demonstrated that crosstalk between uracil incorporation and DNA damage checkpoints was mediated by UDG. When uracil bases were present in DNA, particularly at replication forks, the DNA damage checkpoint appeared to use the ATR/ chk1-cyclin/cdk network to stop damaged cells in the S- or $M$-phase until repairs were made (such as through efficient repair by UDG) or to trigger cell death if repairs could not be made (as in UDG-deficient cells). Second, a fundamental level of coordination between BER and DNA replication is supported by evidence that BER proteins are active during DNA replication. In particular, nuclear UDG has been recently discovered to localize in replication foci to form a multiprotein complex with RPA and PCNA, both of which are involved in various aspects of DNA replication. ${ }^{9,10}$ UDG-initiated BER operates at replication foci, suggesting that UDG-mediated repair may directly and indirectly affect the progression of DNA replication. ${ }^{35}$ Third, a significant increase in the expression of topo $11 \alpha$ was observed in response to pemetrexed exposure. Topoisomerases sustain the progression of the replication machinery by removing supercoils ahead of the replication fork. The induction of topo Il $\alpha$ may indicate that the progression of DNA replication is halted by pemetrexed-induced DNA damage. In UDG ${ }^{-l-}$ cells, $\gamma \mathrm{H} 2 \mathrm{AX}$ and PARP cleavage were concomitantly increased with induction of topo $\| \alpha$, suggesting that replication fork collapse occurs when the replication machinery arrives at the uracil-containing DNA template, leading to cell death. By contrast, $\mathrm{UDG}^{+/+}$cells were more resistant to topemetrexed-induced cell death.

UDG activity determines the levels of AP sites, key targets of MX. When uracil bases are present in DNA, UDG makes almost all of its contacts with the uracil-containing DNA strand. The binding of UDG transiently forces DNA to undergo local distortions to flip out the uracil base. ${ }^{35}$ By contrast, normal bases resist the distortion, so that the UDG active site only allows uracil to bind in extra helical DNA, facilitating the UDG enzymatic excision to produce AP sites. Interestingly, UDG remains bound to the AP site after releasing the uracil base until the AP site is transferred to APE1, thereby displacing UDG from an AP site. In fact, binding of UDG to its AP site result in the inactivation of UDG activity because the dissociation of UDG from the AP site by APE1 is a rate-limiting step. When $M X$ is present, $M X$ rapidly binds to AP sites and makes them unrecognizable by APE1, blocking the crosstalk of APE1 with other BER proteins and interrupting BER activity. Importantly, the failure of recognition of MX-bound AP sites by APE1 would result in trapping/stabilising UDG in DNA. Although speculative, it is possible that the exceptionally strong binding of UDG to MXbound AP sites forms protein-DNA complexes, leading to the obstruction of replication and catastrophic DNA DSBs. This is consistent with our observation that the combination of pemetrexed and MX induced UDG that was predominantly located in the nucleus, accompanied by a significant increase in $\gamma \mathrm{H} 2 \mathrm{AX}$. In addition to stopping the progression of DNA replication, MX-AP sites are also capable of poisoning topo $\| \alpha$ and inducing topo $\| \alpha$-mediated DNA DSBs. ${ }^{36-39}$ Because production of the lethal MX-AP site depends on UDG activity, UDG is an essential factor for MX-potentiation of pemetrexed cytotoxicity.

Targeting UDG/BER enhances cytotoxicity of pemetrexed through a synthetic lethal mechanism. A synthetic lethal mechanism, in which tumor cells, but not normal cells, are specifically targeted for killing is highly attractive. The concept of synthetic lethality is based on the reliance of cancer cells on DNA repair to maintain cell division. Because cancer cells are 'addicted' to DNA repair, ${ }^{40}$ inhibiting DNA repair impedes cancer cell replication, leading to cell death. The present study demonstrates that targeting BER with MX enhances pemetrexed cytotoxicity by the dual 
inactivation of UDG and topo Il $\alpha$, through trapping in MX-AP sites. As the expression of UDG and topo Ilá is much higher in tumor cells than in normal bone marrow cells, ${ }^{33,36}$ the MX-potentiated synergistic killing effect can be exploited to minimize hematopoietic toxicity. Therefore, BER-targeted, synthetic lethal anticancer therapy has important clinical implications.

\section{Materials and Methods}

Cells and reagents. Stable and complete knockdown of UDG expression in DLD1 colon cancer cells (DLD1/UDG ${ }^{-1-}$ cells) was achieved by homologous recombination, as described by Zhang et al..$^{41}$ Briefly, homologous recombination resulted in insertion of a DNA construct containing a series of stop codons within Exon 1 of the UNG gene to interrupt transcription of both the mitochondrial and nuclear UNG isoforms. Recombinant virus was grown in 293T cells and subsequently used to infect DLD1 cells. Selection of positively transfected clones was achieved by the addition of G418 to the culture medium. A second infection of transfected clones with Cre-recombinase adenovirus caused excision of the neomycin-resistant cassette. $D^{\text {flag }}$ cell line was produced by transfection of UDG expression vector in UDG ${ }^{-I-}$ cells to restore UDG activity.

Pemetrexed was obtained from LC Laboratories (Woburn, MA, USA), 5-Fluorouracil and cisplatin were purchased from Sigma-Aldrich (St. Louis, MO, USA) and temozolomide was purchased from Ochem Inc. (Des Plaines, IL, USA). Uracil DNA glycosylase was purchased from New England Biolabs (Ipswich, MA, USA) and APE1 was purchased from Trevigen (Gaitherburg, MD, USA). MX, uracil, and uracil-1,3- ${ }^{15} \mathrm{~N}_{2}$ were purchased from Sigma-Aldrich. MX was dissolved in sterilized water $(\mathrm{pH} 7.0)$ at a stock solution of $2.5 \mathrm{M}$ and stored at $-20^{\circ} \mathrm{C}$. Working solutions were generated before experimental use. Fluorescent dye-labeled 40-mer oligonucleotides containing U:G mispairs were purchased from Operon Biotechnologies (Huntsville, AL, USA).

Colony survival assay. Tumor cells (500-2000/dish) were plated and treated with pemetrexed $(0-400 \mathrm{nM}), 5-\mathrm{FU}(0-20 \mu \mathrm{M})$, temozolomide $(0-1500 \mu \mathrm{M})$, or cisplatin $(0-40 \mu \mathrm{M})$. After 7 days, surviving colonies were stained with methylene blue for $30 \mathrm{~min}$ at room temperature and the colonies containing more than 50 cells were counted to generate survival curves.

Glycosylase activity assay. UDG activity (purified protein or whole-cell extracts) was measured using an oligodeoxynucleotide containing a single uracil.

5'-[HEX]GTAAAACGACGGCCAGTGUATTCGAGCTCGGTACCCGGGG

3'-CATTTTGCTGCCGGTCACGGAAGCTCGAGCCATGGGCCCC[Cy5]

The fluorescent dye-labeled duplex oligonucleotides were incubated with purified UDG at $37^{\circ} \mathrm{C}$ for $30 \mathrm{~min}$, followed by $30 \mathrm{~min}$ incubation with APE1 or with whole-cell extract. The reaction was stopped by incubation at $95^{\circ} \mathrm{C}$ for $5 \mathrm{~min}$. Reaction products, 18-mer fragments, were resolved by electrophoresis on denaturing $20 \%$ polyacrylamide gels ( $7 \mathrm{M}$ urea, $1 \times$ Tris-borate-EDTA). Visualization and quantitation was achieved using a Typhoon 9200 fluorescence Imager (Amersham BioScience, Piscataway, NJ, USA). UDG activity was determined based on fluorescence density quantified using the ImageQuant software (Amersham BioScience).

AP site assay. The number of AP sites was measured using ARP reagent. The assay was performed as previously described. ${ }^{42}$ Briefly, cells $\left(2 \times 10^{6}\right)$ were collected after drug treatment and DNA was extracted. DNA $(10 \mu \mathrm{g})$ was incubated with $15 \mu \mathrm{l}$ of $1 \mathrm{mM}$ ARP (Dojindo Laboratories, Kumamoto, Japan), and then precipitated and washed with ice-cold ethanol. The ARP-labeled DNA was then heat-denatured at $100^{\circ} \mathrm{C}$ for 5 min, quickly chilled on ice and mixed with an equal volume of $2 \mathrm{M}$ ammonium acetate. The DNA was then immobilized on a BA-S 85 nitrocellulose membrane (Schleicher and Schuell, Dassel, Germany) using a minifold II vacuum filter device (Schleicher and Schuell). The membrane was incubated with $0.25 \%$ BSA-PBS containing streptavidin-conjugated horseradish peroxidase (BioGenex, San Ramon, CA, USA) at room temperature for $40 \mathrm{~min}$ with gentle shaking. ARP-labeled AP sites were visualized by chemiluminescence (Amersham) followed by quantitative densitometry using the NIH ImageJ software.

Detection and quantification of uracil using HPLC/MS/MS analysis. $\mathrm{UDG}^{-1-}$ and $\mathrm{UDG}^{+1+}$ cells were exposed to pemetrexed $(10 \mu \mathrm{M})$ or $5-\mathrm{FU}(10 \mu \mathrm{M})$ for $6,24,48$ and $72 \mathrm{~h}$. At indicated time points, cells were harvested and genomic DNA was extracted by phenol/chloroform. DNA $(40 \mu \mathrm{g})$ was incubated with $10 \mathrm{U}$ of purified UDG (New England Biolabs) in $60 \mu \mathrm{l}$ of reaction buffer at $37^{\circ} \mathrm{C}$ for $2 \mathrm{~h}$. The reaction products were dried at $35^{\circ} \mathrm{C}$ in a Turbovap under a stream of nitrogen and reconstituted in $150 \mu \mathrm{l} 90 \%$ acetonitrile. The analyte was retained by an Atlantis Hilic Silica analytical column (Waters Corporation, Milford, MA USA) $(2.1 \times 100 \mathrm{~mm}, 3.5 \mu \mathrm{M})$ and eluted isocratically by a mixture of $90 \%$ acetonitrile and $10 \% 2.0 \mathrm{mM}$ ammonium formate at a flow rate of $0.2 \mathrm{ml} / \mathrm{min}$. The detection was carried out by an API 3200 MS/MS mass spectrometer (AB SCIEX, Foster City, CA, USA).

Immunofluorescence microscopy. Cells were grown on coverslips and were treated with drugs for $6-24 \mathrm{~h}$. Then cells were fixed in $2 \%$ paraformaldehyde and permeabilized with $0.2 \%$ Triton $X-100$. Cells were incubated with primary UDG (Abcam, Cambridge, MA, USA) or $\gamma \mathrm{H} 2 \mathrm{AX}$ (Bethyl, Montgomery, TX, USA) antibody for $1 \mathrm{~h}$ at room temperature, followed by incubation with a secondary antibody conjugated with Alexa 488 (green) (Molecular Probes, Carlsbad, CA, USA). The nucleus was stained using Hoechst 33258 for $15 \mathrm{~min}$ at room temperature. Images were digitally captured using an Olympus microscope (Olympus, Westmont, IL, USA) equipped with a digital camera.

Western blot analysis. Cellular protein was quantified spectrophotometrically using the Bio-Rad assay. Equal amounts of proteins $(30 \mu \mathrm{g})$ were separated by SDS-PAGE and transferred to polyvinylidene fluoride membrane (Millipore Corp., Bedford, MA, USA). The membrane was incubated with primary antibody in $1 \%$ nonfat dry milk solution overnight at $4^{\circ} \mathrm{C}$ and followed by the incubation with HRPconjugated secondary antibody at room temperature for $1 \mathrm{~h}$. Proteins were visualized by ECL (Amersham Corp, Piscataway, NJ, USA) according to the manufacturer's instructions. Sources of primary antibody were as follows: cleaved PARP (BD Pharmingen, San Jose, CA, USA), $\gamma$ H2AX (Bethyl), pChk1, Chk1, pcdc2, cyclin B1, topo Il $\alpha$, topoisomerase I, Bax, and Bcl2 (Cell Signaling, Danvers, MA, USA), phospho-histone H3 (Upstate Biotechnologies, Billerica, MA, USA) and $\alpha$-tubulin (Sigma-Aldrich).

Cell cycle analysis. For cell cycle analysis, $10^{6}$ cells (DLD1/UDG ${ }^{+/+}$and DLD1/UDG ${ }^{-1-}$ ) were plated in 100-mm tissue culture dishes and exposed to pemetrexed $(25 \mathrm{nM})$. After 6,24 , and $72 \mathrm{~h}$ of culture, cells were fixed with $80 \%$ methanol and washed with ice-cold $1 \%$ BSA/PBS. DNA was stained with $20 \mu \mathrm{g} / \mathrm{ml}$ propidium iodide (Sigma-Aldrich) and $2.5 \mu \mathrm{g} / \mathrm{ml}$ of DNase-free RNaseA (Roche, Branford, CT, USA). The DNA fluorescence of propidium iodide-stained cells was measured with an Elite ESP flow cytometer/cell sorter (Coulter, Miami, FL, USA).

Immunofluorescence microscopy of replication foci stained with CldU and IdU. DNA replication sites were visualized by incorporation of CldU and IdU into DNA. UDG ${ }^{-1}$ and $\mathrm{UDG}^{+/+}$cells were labeled with $100 \mu \mathrm{M}$ CldU (ICN, Irvine, CA, USA) or IdU (Sigma-Aldrich) for $45 \mathrm{~min}$ at different time intervals. Cells were washed with PBS, fixed with cold $70 \%$ ethanol and stored at $4{ }^{\circ} \mathrm{C}$. For antibody staining, the ethanol was removed, and $100 \%$ methanol was added for $5 \mathrm{~min}$. Cells were washed twice with PBS and incubated with $1.5 \mathrm{M} \mathrm{HCl}$ for $30 \mathrm{~min}$ to denature the DNA. Cells were washed with PBS, permeabilized with $0.5 \%$ Tween-20 in PBS for $5 \mathrm{~min}$, and then incubated in 5\% BSA (Sigma-Aldrich) and in PBS for $20 \mathrm{~min}$ to reduce nonspecific binding. Primary antibodies CldU (rat antiBrdU; Accurate Chemical and Science Co., Westbury, NY, USA) and IdU (mouse anti-BrdU; BD Biosciences) were diluted in $1 \%$ BSA buffer, added to the slides, and incubated in a humid environment for $2 \mathrm{~h}$. Slides were washed with PBS-Tween20 and then in a high-salt buffer $(200 \mathrm{mM} \mathrm{NaCl}, 0.2 \%$ Tween-20, and $0.2 \% \mathrm{NP}-40$ in PBS) for $15 \mathrm{~min}$. The samples were incubated with secondary antibodies for $1 \mathrm{~h}$. Finally, slides were washed with PBS-Tween 20, mounted with Vectashield antifade mounting medium (Vector Laboratories, Inc., Burlingame, CA, USA), and stored at $4^{\circ} \mathrm{C}$. Images were visualized on a Nikon EclipseTE-300 confocal microscope (Jenoptik Laser Technologies Corp., Brighton, MI, USA). Fluorescence density of CldU or IdU was quantified by the NIH Image $\mathrm{J}$ software.

Xenograft tumors in nude mice. $\mathrm{H} 460$ or A549 tumor cells $\left(5 \times 10^{6}\right)$ were injected into bilateral flanks of female athymic $\mathrm{NCr}$ (nu/nu) mice ( 6 weeks old). When the tumor volumes reached $100-150 \mathrm{~mm}^{3}$, mice were divided into control and treatment groups (6-9 mice/group). Nude mice carrying tumors were treated with pemetrexed $(150 \mathrm{mg} / \mathrm{kg})$ alone, MX $(4 \mathrm{mg} / \mathrm{kg})$ alone, or the combination of the two agents, by daily intraperitonial injection (i.p.) for 5 consecutive days. Tumor measurements were taken every 2 days. Tumor responses were quantified by tumor volume. 
Statistical analysis. Results are presented as the mean \pm s.e.m. with significance calculated by Student's $t$-test with standard software (GraphPad Prism, San Diego, CA, USA). Significance was assigned for a $P$-value $<0.05$.

\section{Conflict of Interest}

Stanton Gerson and Lili Liu own a patent on the methoxyamine. The intellectual property of methoxyamine is licensed by Tracon Pharmaceutical Inc.

Acknowledgements. This study was supported by the research grant sponsored by Tracon Pharmaceutical Company and the National Cancer Institute grants CA86357, CA82292, and CA43703.

1. Hanauske AR, Chen V, Paoletti P, Niyikiza C. Pemetrexed disodium: a novel antifolate clinically active against multiple solid tumors. Oncologist 2001; 6: 363-373.

2. Goldman DL, Zhao R. Molecular, biochemical and cellular pharmacology of pemetrexed. Semin Oncol 2002; 29: S3-S17.

3. Houghton JA, Weiss KD, Williams LG, Torrance PM, Houghton PJ. Relationship between 5-fluoro-2'-deoxyuridylate, 2'-deoxyuridylate, and thymidylate synthase activity subsequent to 5 -fluorouracil administration in xenografts of human colon adenocarcinomas. Biochem Pharmacol 1986; 35: 1351-1358.

4. Krokan HE, Standal R, Slupphaug G. DNA glycosylases in base excision repair of DNA. Biochem J 1997; 325: 1-16.

5. Yoon JH, Iwai S, O'Connor TR, Pfeifer GP. Human thymine DNA glycosylase (TDG) and methyl-CpG-binding protein 4 (MBD4) excise thymine glycol (Tg) from a Tg:G mispair. Nucleic Acids Res 2003; 31: 5399-5404.

6. Krokan HE, Drablos F, Slupphaug G. Uracil in DNA-occurrence, consequences and repair. Oncogene 2002; 21: 8935-8948.

7. Olsen LC, Aasland R, Wittwer CU, Krokan HE, Helland DE. Molecular cloning of human uracil-DNA glycosylase, a highly conserved DNA repair enzyme. EMBO J 1990; 8 : 3121-3125.

8. Nilsen $\mathrm{H}$, Otterlei M, Haug $\mathrm{T}$, Solum $\mathrm{K}$, Nagelhus TA, Skorpen $\mathrm{F}$ et al. Nuclear and mitochondrial urail-DNA glycosylases are generated by alternative splicing and transcription from different positions in the UNG gene. Nucleic Acids Res 1998; 25: 750-755.

9. Hagen L, Kavli B, Sousa MM, Torseth K, Liabakk NB, Sundheim O et al. Cell cycle-specific UNG2 phosphorylations regulate protein turnover, activity and association with RPA. EMBO J 2008; 27: 51-61

10. Otterlei M, Warbrick E, Nagelhus TA, Haug T, Slupphaug G, Akbari M et al. Post-replicative base excision repair in replication foci. EMBO J 1999; 18: 3834-3844.

11. Dionne I, Bell SD. Characterization of an archaeal family 4 uracil DNA glycosylase and its interaction with PCNA and chromatin proteins. Biochem J 2005; 387: 859-863.

12. Zeitlin SG, Chapados BR, Baker NM, Tai C, Slupphaug G, Wang JY. Uracil DNA $\mathrm{N}$-glycosylase promotes assembly of human centromere protein A. PLoS One 2011; 6: e17151.

13. Fortini $P$, Parlanti E, Sidorkina OM, Laval J, Dogliotti E. The type of DNA glycosylase determines the base excision repair pathway in mammalian cells. J Biol Chem 1999; 274: $15230-15236$

14. Hoeijmakers JH. Genome maintenance mechanisms for preventing cancer. Nature 2001; 411: $366-374$

15. Matray TJ, Kool ET. A specific partner for abasic damage in DNA. Nature 1999; 399 : 704-708.

16. Horton JK, Prasad R, Hou E, Wilson SH. Protection against methylation-induced cytotoxicity by DNA polymerase $\beta$-dependent long patch base excision repair. J Biol Chem 2000; 275: 2211-2218.

17. Rinne M, Caldwell D, Kelley MR. Transient adenoviral N-methylpurine DNA glycosylase overexpression imparts chemotherapeutic sensitivity to human breast cancer cells. Mol Cancer Ther 2004; 3: 955-967.

18. Fishel ML, He Y, Smith ML, Kelley MR. Manipulation of base excision repair to sensitize ovarian cancer cells to alkylating agent temozolomide. Clin Cancer Res 2007; 13: 260-267.

19. Liu L, Gerson SL. Therapeutic impact of methoxyamine: blocking repair of abasic sites in the base excision repair pathway. Curr Opin Investig Drugs 2004; 5: 623-627.

20. Liuzzi M, Talpaert-Borle M. A new approach to study of the base excision repair pathway using methoxyamine. J Biol Chem 1985; 260: 5252-5258.
21. Rosa S, Fortini $\mathrm{P}$, Karran $\mathrm{P}$, Bignami M, Dogliotti $\mathrm{E}$. Processing in vitro of an abasic site reacted with methoxyamine: a new assay for the detection of abasic sites formed in vivo. Nucleic Acids Res 1991; 19: 5569-5574.

22. Liu L, Taverna P, Whitacre CM, Chatterjee S, Gerson SL. Pharmacological disruption of base excision repair sensitizes mismatch repair deficient and proficient colon cancer cells to methylating agents. Clin Cancer Res 1999; 5: 2908-2917.

23. Liu L, Gerson SL. Base excision repair as a therapeutic target in colon cancer. Clin Cancer Res 2002; 8: 2985-2991.

24. Liu L, Yan L, Donze JR, Gerson L. Blockage of abasic site repair enhances antitumor efficacy of 1,3-bis-(2-chloroethyl)-1-nitrosourea in colon tumor xenografts. Mol Cancer Ther 2003; 2: 1061-1066.

25. Taverna P, Hwang HS, Schupp JE, Radivoyevitch T, Nguyen N, Reddy G et al. Inhibition of base excision repair potentiates iododeoxyuridine-induced cytotoxicity and radiosensitization. Cancer Res 2003; 63: 838-846.

26. Nowak SJ, Corces VG. Phosphorylation of histone H3: a balancing act between chromosome condensation and transcriptional activation. Trends Genet 2004; 20 214-220.

27. Ewald B, Sampath D, Plunkett W. H2AX phosphorylation marks gemcitabineinduced stalled replication forks and their collapse upon S-phase checkpoint abrogation Mol Cancer Ther 2007; 6: 1239-1248.

28. Tamm I, Wang Y, Sausville E, Scudiero DA, Vigna N, Oltersdorf T et al. IAP-family protein survivin inhibits caspase activity and apoptosis induced by Fas (CD95), Bax, caspases, and anticancer drugs. Cancer Res 1998; 58: 5315-5320.

29. de Bruin EC, Meersma D, de Wilde J, den Otter I, Schipper EM, Medema JP et al. A serine protease is involved in the initiation of DNA damage-induced apoptosis. Cell Death Differ 2003; 10: 1204-1212.

30. Garber ME, Troyanskaya OG, Schluens K, Petersen S, Thaesler Z, Pacyna-Gengelbach M et al. Diversity of gene expression in adenocarcinoma of the lung. Proc Natl Acad Sci USA 2001; 98: 13784-13789.

31. Bhattacharjee A, Richards WG, Staunton J, Li C, Monti S, Vasa $P$ et al. Classification of human lung carcinomas by mRNA expression profiling reveals distinct adenocarcinoma subclasses. Proc Natl Acad Sci USA 2001; 98: 13790-13795.

32. Basso K, Margolin AA, Stolovitzky G, Klein U, Dalla-Favera R, Califano A. Reverse engineering of regulatory networks in human B cells. Nat Genet 2005; 37: 382-390.

33. Yan L, Bulgar AD, Miao YL, Mahajan V, Donze JR, Gerson SL et al. Combined treatment with temozolomide and methoxyamine: blocking apurinic/pyrimidinic site repair coupled with targeting topoisomerase Il $\alpha$. Clin Cancer Res 2007; 13: 1532-1539.

34. Parikh S, Mol CD, Slupphaug G, Bharati S, Krokan HE, Tainer JA. Base excision repair initiation revealed by crystal structures and binding kinetics of human uracil-DNA glycosylase with DNA. EMBO J 1998; 17: 5214-5226.

35. Parlanti E, Locatelli G, Maga G, Dogliotti E. Human base excision repair complex is physically associated to DNA replication and cell cycle regulatory proteins. Nucleic Acids Res 2007; 35: 1569-1577.

36. Bulgar AD, Snell M, Donze JR, Kirkland EB, Li L, Yang S et al. Targeting base excision repair suggests a new therapeutic strategy of fludarabine for the treatment of chronic lymphocytic leukemia. Leukemia 2010; 24: 1795-1799.

37. Kingma PS, Osheroff N. Apurinic sites are position specific topoisomerase Il-poisons. J Biol Chem 1997; 272: 1148-1155.

38. Nitiss JL. DNA topoisomerase II and its growing repertoire of biological functions. Nat Rev Cancer 2009; 9: 327-337.

39. Lucas I, Germe T, Chevrier-Miller M. Topoisomerase II can unlink replicating DNA by precatenane removal. Nat Rev Cancer 2001; 20: 6509-6519.

40. Shaheen M, Allen C, Nickoloff JA, Hromas R. Synthetic lethality: exploiting the addiction of cancer to DNA repair. Blood 2011; 117: 6074-6082.

41. Zhang GC, Fink SP, Wilson K, Willson JK, Wang Z, Markowitz SD. Ugene, a newly identified protein that is commonly overexpressed in cancer and binds uracil DNA glycosylase. Cancer Res 2008; 68: 6118-6126.

42. Nakamura J, Swenberg JA. Endogenous apurinic/apyrimidinic sites in genomic DNA of mammalian tissues. Cancer Res 1999; 59: 2522-2526.

Cell Death and Disease is an open-access journal published by Nature Publishing Group. This work is licensed under the Creative Commons Attribution-Noncommercial-No Derivative Works 3.0 Unported License. To view a copy of this license, visit http://creativecommons.org/licenses/by-nc-nd/3.0/ 